\title{
Progressive Restriction of Synaptic Vesicle Protein to the Nerve Terminal During Development of the Neuromuscular Junction
}

\author{
Mark T. Lupa a and Zach W. Hall \\ Department of Physiology, University of California San Francisco, San Francisco, California 94143
}

\begin{abstract}
Antibodies to synaptic vesicle (SV) proteins and to neurofilament (NF) proteins were used to investigate presynaptic differentiation and its relation to the formation of acetylcholine receptor (AChR) clusters at developing mouse neuromuscular junctions. At all times during development, SV proteins and NF proteins were segregated into neighboring, but separate regions of the presynaptic neurite. At embryonic day (ED) 14 SV proteins were present throughout preterminal neurites but at later ages became progressively restricted to the distal parts of the neurites. NF proteins occupied a more proximal region that extended distally during development until NF proteins occupied the entire axon up to the terminal. The restriction of SV proteins exclusively to the terminal did not occur until the second postnatal week. At the time of their first appearance (ED 14), up to $50 \%$ of AChR clusters were not associated with neurites; precise colocalization required $12-36 \mathrm{hr}$ to develop. These findings demonstrate a progressive restriction of both pre- and postsynaptic components to the synapse during development.
\end{abstract}

A striking feature of the adult neuromuscular junction is the segregation of specific proteins into specialized regions of both pre- and postsynaptic cells (for reviews, see Dennis, 1981; Reichardt and Kelly, 1983; Salpeter and Loring, 1986). Acetylcholine receptors (AChRs), for example, are restricted to the crests of the postsynaptic folds at the adult neuromuscular junction, where their concentration is more than 1000 -fold higher than in the extrajunctional membrane (Fertuck and Salpeter, 1976). During muscle development, AChRs are initially diffusely distributed on the myotube surface but become clustered at high density near sites of nerve-muscle contact (Bevan and Steinbach, 1977; Braithwaite and Harris, 1979).

A similar segregation occurs in presynaptic axons in which proteins and organelles that function in neurotransmitter release are concentrated in nerve terminals. Synaptic vesicles at the mature neuromuscular junction, for example, are highly concentrated at active zones in the terminal (Couteaux and PecotDechavassine, 1970). Several identified proteins associated with synaptic vesicles have been shown by immunocytochemistry to

\footnotetext{
Received Mar. 2, 1989; revised May 11, 1989; accepted May 16, 1989.

We would like to thank Drs. L. Reichardt, K. Buckley, and R. Kelly of UCSF for generously providing monoclonal antibodies. We also express our gratitude to Dr. Y. Gu for help with the Western blot and to Dr. H. Gordon for help with the MacFigures. This work was supported by grants from the Muscular Dystrophy Association and the National Institutes of Health.

Correspondence should be addressed to Z. W. Hall at the above address.

a Present address: University of Colorado, Health Science Centre, Department of Cellular and Structural Biology, 4200 E. Ninth Avenue, Denver, CO 80262

Copyright (C) 1989 Society for Neuroscience $0270-6474 / 89 / 113937-09 \$ 02.00 / 0$
}

be concentrated in nerve terminals. These include SV2, SV65, synaptophysin, and synapsin I (Matthew et al., 1981; De Camilli et al., 1983; Buckley and Kelly, 1985; Wiedenmann and Franke, 1985). Although several groups have used antibodies to synaptic vesicle (SV) proteins as neuronal markers in vitro (Bixby and Reichardt, 1985; Cohen et al., 1987) and in vivo (Vijay Sarthy and Bacon, 1985; Mason, 1986; Chun and Shatz, 1988), little is known about how their specific localization in nerve terminals arises during synaptogenesis.

We have used antibodies to investigate the distribution of SV proteins during formation of the neuromuscular junction. We have compared their distribution both with that of neurofilament (NF) proteins and that of AChRs in the postsynaptic membrane. Neurofilaments of $10 \mathrm{~nm}$ diameter are found in the axons and dendrites of nerve cells, where they are thought to provide structural support (Shaw, 1987). They consist of 3 peptide subunits (approximately 60,160 , and $200 \mathrm{kDa}$ ), which are unique to neurons and are members of the intermediate filament protein family. By examining the distribution of AChRs, NF, and SV proteins during synaptogenesis, we were able to follow the differentiation of the nerve terminal both with respect to the postsynaptic membrane and the rest of the axon. Our principal finding is that synaptic vesicles are initially widely distributed in presynaptic neurites and become progressively restricted to the terminals in a process that is only completed postnatally.

\section{Materials and Methods}

Whole mounts. Timed pregnant C57BL6 mice were obtained from Simonsen Co. (San Francisco). Mothers were killed by cervical dislocation, and the embryonic sacs were removed and placed in a $60 \mathrm{~mm}$ culture dish containing ice-cold DISGH solution (Pucks D1 salt solution (GIB$\mathrm{CO}$ ), $6 \mathrm{gm} /$ /iter glucose, $15 \mathrm{gm} /$ liter sucrose, $10 \mathrm{~mm}$ Hepes, $1 \%$ penstrep, $\mathrm{pH}$ 7.3). Diaphragms were carefully removed along with attached ribs and a length of nerve and pinned caudal-side up in a $35 \mathrm{~mm}$ dish coated with Sylgard. Immunofluorescent staining was carried out in these dishes.

Frozen sections. Mice and rats were killed by cervical dislocation, and diaphragms were quickly dissected into cold PBS. The endplate band in the middle third of the muscle was isolated and cut into $1 \mathrm{~cm}$ strips. Three such strips were stacked on aluminum foil and frozen in a vat of liquid nitrogen. Cryostat sections of 4-8 $\mu \mathrm{m}$ thickness were cut onto cleaned microscope slides, as previously described (Sanes and Hall, 1979).

Immunofluorescence. Indirect immunocytochemical staining was accomplished with a method modificd from Froehner et al. (1987). Preparations were incubated with $50 \mathrm{nM}$ rhodamine-conjugated $\alpha$-bungarotoxin (rho-Butx) in FM EDMEM (GIBCO), 5\% inactivated horse serum at $37^{\circ} \mathrm{C}$ for $1 \mathrm{hr}$. After 3 washes with PBS, the cells were fixed in 3\% paraformaldehyde in PBS with $0.075 \%$ saponin, $\mathrm{pH} 7.3$, for 20 min at room temperature, rinsed with PBS twice, and treated with 0.1 $M$ glycine for $30 \mathrm{~min}$. Tissues were permeabilized by incubation with $0.5 \%$ Triton $\mathrm{X}-100 / \mathrm{PBS}$ for $10 \mathrm{~min}$, and subsequently incubated in 


\section{NF160}

Figure 1. Specificity of mAbs on immunoblots against the middle MW (160 $\mathrm{kDa}$ ) subunit of neurofilaments (NF160), the middle and high MW (200 $\mathrm{kDa}$ ) subunits of neurofilaments $(N F)$, and the synaptic vesicle glycoprotein $S V 2$. Crude extracts of mouse liver (lane 1), spinal cord (lane 2), sciatic nerve (lane 3), diaphragm muscle endplate area (lane 4), and diaphragm muscle extrajunctional area (lane 5) were subjected to immunoblotting as described in Materials and Methods. Approximately $60 \mu \mathrm{g}$ protein was loaded per lane. Numbers on the right correspond to molecular mass in kilodaltons.

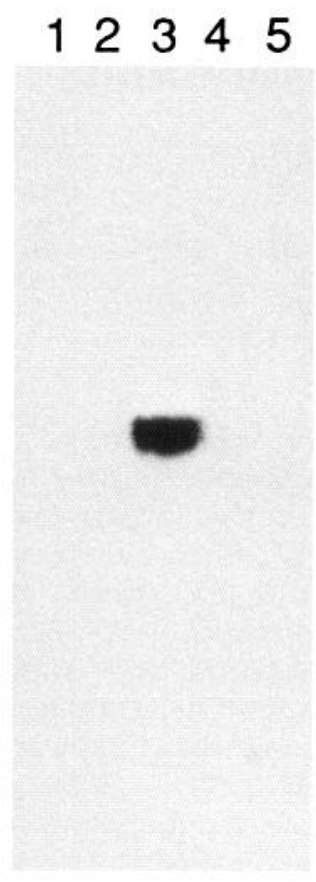

PBS/ $10 \%$ fetal bovine serum $/ 4 \%$ BSA for 15 min to inhibit nonspecific binding of antibodies. Preparations were then incubated with primary antibody overnight at $4^{\circ} \mathrm{C}$, washed with PBS, incubated for $1 \mathrm{hr}$ with FITC- or aminomethylcoumarin acetic acid (AMCA)-coupled second antibody at room temperature, and rinsed again with PBS. The muscles were mounted on glass slides with a glycerol-based solution containing p-phenylenediamine (Platt and Michael, 1983) and viewed with a Leitz Orthoplan II microscope under epifluorescent illumination. For frozen sections the initial fixation and permeabilization steps were omitted.

Control incubations were with affinity-purified mouse $\mathrm{IgG}$ at a concentration of $1 \mu \mathrm{g} / \mathrm{ml}$ substituted for the first antibody. No staining above background was observed under these conditions.

Histochemical markers. Two different antibodies against NF protein were used. A monoclonal antibody (mAb NN18) against the $160 \mathrm{kDa}$ subunit of bovine neurofilaments (Shaw et al., 1984) was obtained from Boehringer-Mannheim, and ascites fluid from hybridoma NRV170 was acquired from Enzo Biochem (New York). NRV170 has been shown to recognize the middle and high MW subunits (160 and $200 \mathrm{kDa})$ of NFs in Western blots of rat and human brain (Gown and Vogel, 1984).

Three different antibodies against SV antigens were employed; no qualitative differences in staining were observed between them. A mAb (SY 38) to synaptophysin, purchased from Boehringer-Mannheim, recognizes a $38 \mathrm{kDa}$ band in Western blots of mammalian brain proteins (Wiedenmann and Franke, 1985). mAb 48, against a $65 \mathrm{kDa}$ SV membrane protein (SV65), which has been shown to be associated with vesicles in most and possibly all neurons (Matthew et al., 1981), was kindly provided by Dr. L. Reichardt. An mAb to the SV membrane glycoprotein SV2, generously supplied by Drs. K. Buckley and R. Kelly, binds specifically to SVs purified from electric organ and immunoprecipitates a $62 \mathrm{kDa}$ band from PC12 cells (Buckley and Kelly, 1985).

Rho-Butx was prepared according to Ravdin and Axelrod (1977). Polyclonal secondary antibodies were purchased from Cappel Co. (USA) and conjugated to AMCA (a UV fluorophore obtained from Molecular Probes, Eugene, OR) according to the method of Wessendorf et al. (1987).

SDS-PAGE and immunoblotting analysis. The specificities of the $\mathrm{mAbs}$ to the $160 \mathrm{kDa}$ subunit of NFs (NF160), the middle- and highMW subunits of NF, and the SV glycoprotein SV2 (SV2) were tested since these were the antibodies most often used. Mouse liver, sciatic nerve, spinal cord, and diaphragm muscle were extracted with $1 \%$ SDS, and the extracts were subjected to SDS-PAGE on a 5-10\% gradient gel,
NF

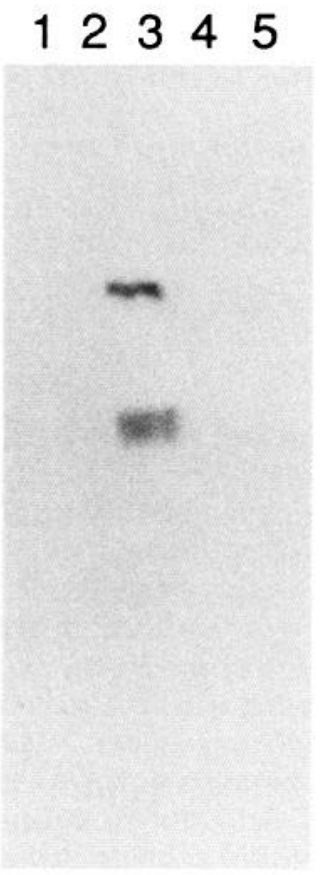

SV 2

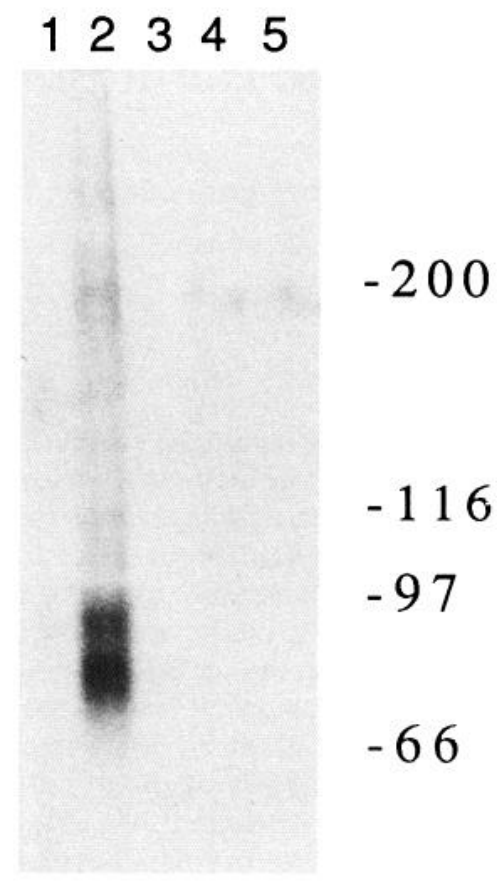

as described by $\mathrm{Gu}$ and Hall (1988). The proteins were electrophoretically transferred onto nitrocellulose membranes with a Hoefer apparatus (model TE50) using $20 \mathrm{~mm}$ Tris-base buffer with $150 \mathrm{~mm}$ glycine and $20 \%(\mathrm{vol} / \mathrm{vol})$ methanol. After incubation with $0.3 \%(\mathrm{vol} / \mathrm{vol})$ Tween 20 , the nitrocellulose was incubated with appropriately diluted primary antibody for $8-12 \mathrm{hr}$ at room temperature, followed by $2 \mathrm{hr}$ incubations with rabbit anti-mouse IgG and then with ${ }^{125} \mathrm{I}$-labeled goat anti-rabbit IgG. As shown in Figure 1, both anti-NF and anti-NF160 antibodies recognized a narrow band at approximately $145 \mathrm{kDa}$; anti-NF also stained a band at around $200 \mathrm{kDa}$. The SV 2 monoclonal recognized 2 broad bands at about 70 and $90 \mathrm{kDa}$. Only the extract of sciatic nerve stained strongly for NF and NF160, with a weak band appearing in the spinal cord lane. Anti-SV2 staining was restricted to the spinal cord lane. No cross-reactivity was noted for any of the antibodies with extracts of liver or muscle.

\section{Results}

The distributions of NF proteins, SV proteins, and AChRs were examined in adult and developing muscle. Two different mAbs were used to visualize NF proteins (see Materials and Methods); similar results were obtained with each. An mAb against SV2 was used to determine the distribution of SV proteins in most experiments. Qualitatively similar results were obtained with antibodies against 2 other SV proteins, SV65 and synaptophysin (see Materials and Methods). Unless otherwise noted, all results shown were obtained with the antibodies to the middle (160 $\mathrm{kDa}$ )-MW subunit of NFs and to the SV protein SV2. We assume that the proteins recognized by these $\mathrm{mAbs}$ are associated with NFs and synaptic vesicles, respectively (see Hirokawa et al., 1984; Buckley and Kelly, 1985).

\section{Distribution of $N F$ and $S V$ proteins}

Adult muscle. Both frozen cross sections and whole-mount preparations were examined to determine the distribution of NF and SV proteins in presynaptic axons of adult muscle. Our results showed that these proteins have almost precisely complemen- 


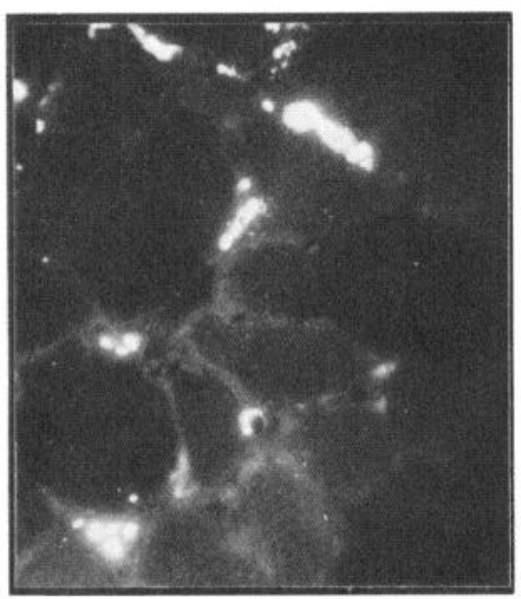

NF

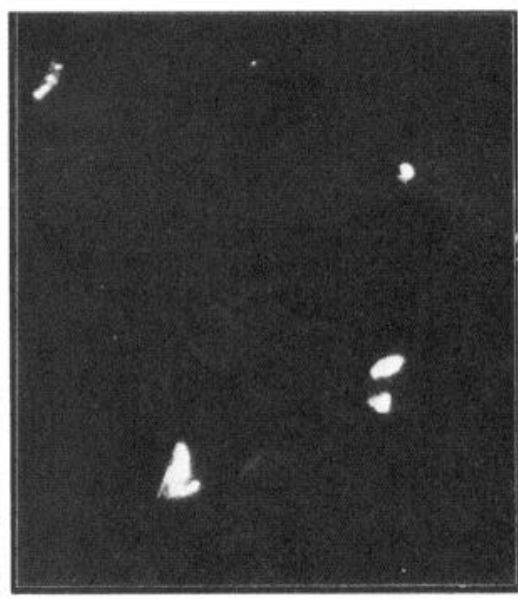

SV

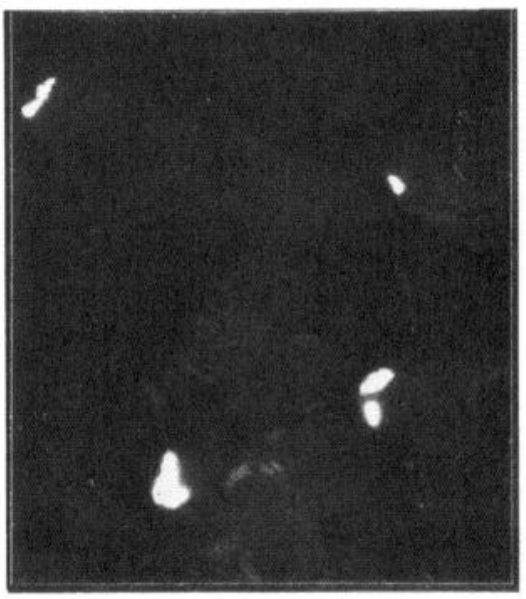

rho-Butx

Figure 2. Frozen transverse sections of adult mouse diaphragm were simultaneously labeled with rhodamine-conjugated $\alpha$-bungarotoxin (rho$B u t x)$, and with antibodies to NF proteins $(N F)$ and to the synaptic vesicle glycoprotein SV2 $(S V)$. Note the close correspondence between the SV and rho-Butx fluorescence, and the lack of correspondence between NF immunofluorescence and either SV or rho-Butx staining.

tary distributions. In triple-label experiments on cross sections of adult mouse diaphragm muscle, the pattern of immunofluorescence for SV protein was virtually identical to that of rhoButx, with arcs of intense fluorescence on one edge of scattered muscle fibers, signaling the location of neuromuscular junctions (Fig. 2). In contrast, anti-NF fluorescence was generally not coincident with rho-Butx or anti-SV fluorescence but was confined to the large nerve trunks and small nerve branches lying between the muscle fibers. Thus, in the adult, NF protein and SV protein appear to be localized to different regions of the motor axon.

The relative exclusion of NF protein from the motor nerve terminal was best demonstrated in whole mounts of adult diaphragm muscle (Fig. 3). In intact mouse diaphragm, SV protein immunofluorescence was confined to the nerve terminal area, which corresponded precisely to the motor endplate area as revealed with rho-Butx (results not shown). NF fluorescence was strong in the preterminal axon, with weak fluorescence in the proximal edge portions of the nerve terminal. Most of the nerve terminal area, however, was free of anti-NF fluorescence. A similar distribution of NF protein at adult neuromuscular junctions has recently been reported by De Camilli et al. (1988) and Donahue et al. (1988).

Developing muscle. Intact diaphragms from embryonic and neonatal mice were examined by double-label immunofluorescence to determine when the restricted distribution of NF and SV proteins arises during development. In muscles from ED 14-15 mice, at a time when the earliest synaptic potentials can be recorded in rats (Dennis et al., 1981), weak staining for NF protein was visible but was confined to the main nerve trunk that traverses the muscle (Fig. 4, ED 14.5). Antibodies to SV protein, in contrast, bound not only to the nerve trunk, but also to short neurites branching from it. Staining for SV protein appeared to be particularly prominent at growth cones. During all stages of development, anti-NF fluorescence was uniform when present, whereas SV protein fluorescence customarily occured in patches, giving the neurites a beaded appearance (Fig. 4).

In muscles from ED 16-18 embryos, NF protein staining was stronger but remained confined to the main nerve trunk (Fig. 4, ED 16.5). At this time, neurites leaving the trunk were stained more strongly by SV protein antibody and could be seen to have extended and branched over the myotubes. Around the time of birth (Fig. 4, PN 2), NF protein staining could be clearly observed in the neurites leaving the main nerve trunk. Oval accumulations of SV protein had formed on muscle fibers; short lengths of neurite leading to or connecting the immature nerve terminals, however, were still stained for SV protein. Also prominent at this stage were neurite sprouts staining for SV protein that originated from nerve terminals and extended long distances along muscle fibers (Figs. 4, 5).

In the second and third weeks after birth, the nerve terminal sprouts disappeared, and SV protein became entirely confined to the nerve terminals (Fig. 4, PN 23). The terminal region at this stage assumed the complex configuration seen in the adult. During the postnatal period, staining for NF protein gradually intensified along the entire length of neurite leading to the nerve terminal, until at PN 23 a few strands of weak NF staining could be observed at the proximal edges of the nerve terminal (Fig. 4).

These results with developing muscle show that, from the time of first neuronal contact with muscle fibers, NF and SV proteins have distinctive axonal distributions. SV protein is initially present in neurites and growth cones, and only becomes confined to the terminals during the postnatal period. NF protein is initially not present in the neurites that grow from the main nerve trunk, but progressively extends out toward the terminals during development.

\section{Relation of AChR clusters to presynaptic antigens}

Adult muscle. As seen in Figure 2, the distribution of AChR in adult muscle was precisely coincident with that of the presynaptic terminals, as visualized by antibodies to SV proteins.

Developing muscle. The correspondence between AChR and SV protein was examined in developing muscle using doublelabel immunofluorescence of mouse diaphragms in whole mount. Patches of AChR were first detected in muscles from ED 1415 mice. At this time, the short SV-containing neurites were 


\section{rho-Butx}

Figure 3. Antibody staining of neuromuscular junctions in intact muscle. Adult mouse diaphragms were labeled with antibodies to NF protein $(N F)$ and with rhodamine-conjugated $\alpha$-bungarotoxin (rho-Butx). The bottom panel is a superimposed tracing of the 2 fluorescence patterns, showing NF fluorescence in the preterminal axon and the proximal edges of the nerve terminal.

first visible, and the first AChR clusters appeared as an irregular band in the near vicinity of these short neurites (Fig. 5). Only about half of the AChR clusters were precisely aligned with the growing $\mathrm{SV}$-accumulating neurites at this stage.

Over the following $2 \mathrm{~d}$, all AChR patches became precisely aligned with the SV-containing neurites. These neurite-associated receptor clusters (NARCs) were usually found along the terminal segment of the SV-positive neurites but were sometimes associated with central segments of neurites growing along or over myotubes. Occasionally, a single neurite could be found aligned with NARCs on several adjacent fibers (Fig. 5, ED 17). The nerve terminal sprouts observed in neonatal muscles were never seen to be associated with AChR clusters. At adult neuromuscular junctions rho-Butx stained intensely, and in a pattern identical to anti-SV (Fig. 5). Only faint wisps of NF found in the proximal segment of the nerve terminal colocalized with part of the endplate rho-Butx.
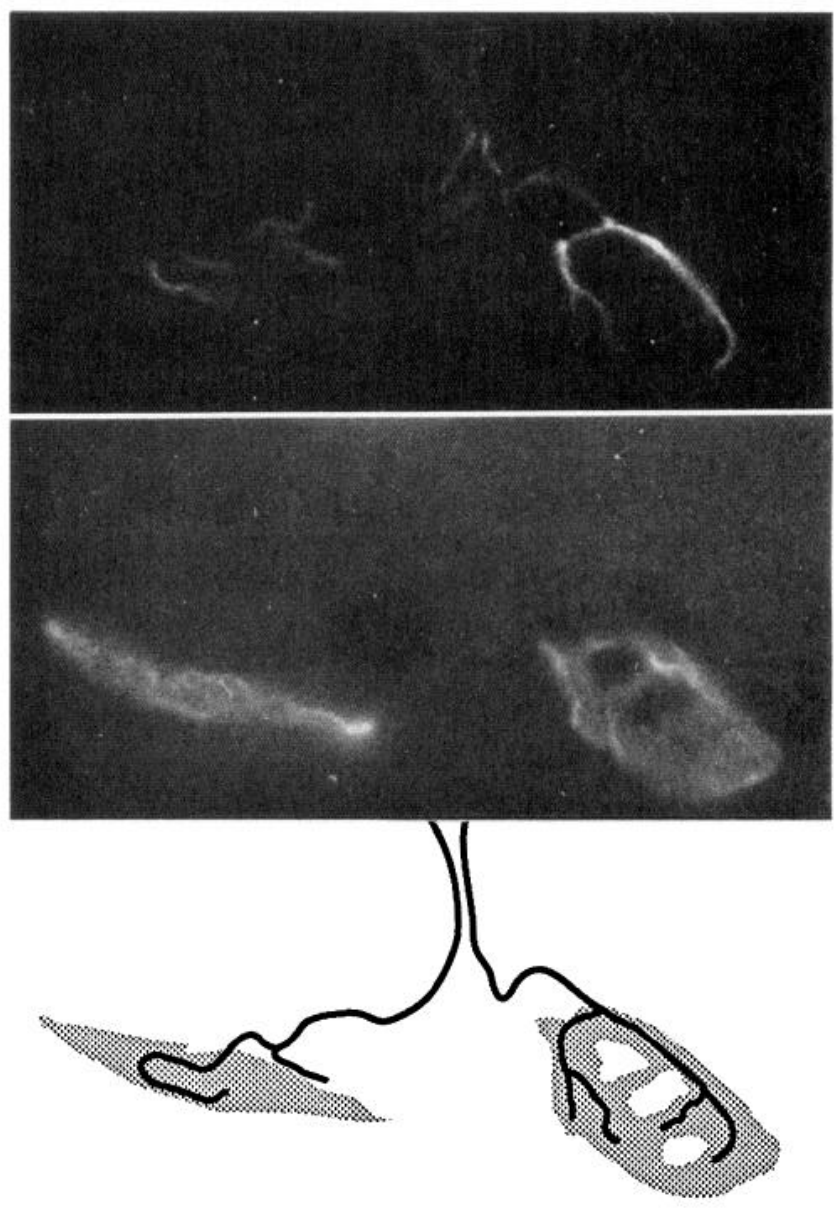

\section{Discussion}

The primary objective of these experiments was to investigate synaptic differentiation at the neuromuscular junction in vivo using histochemical markers to both pre- and postsynaptic components. Although differentiation of the postsynaptic cell surface has been frequently studied (Fambrough, 1979; Salpeter and Loring, 1986), little is known about presynaptic differentiation at this synapse. By examining both pre- and postsynaptic differentiation simultaneously, we were able to obtain important information about the temporal and spatial correspondence between them.

\section{SV protein}

The results clearly showed that SV protein is not confined to nerve terminals or to sites of immature synaptic contact during the early stages of neuromuscular development. During early

Figure 4. Distribution of NF and SV proteins at developing neuromuscular junctions. Intact mouse diaphragms from mice of different ages were labeled with antibodies to SV2 $(S V)$ and the $160 \mathrm{kDa}$ subunit of neurofilament protein $(N F)$. In each case, the same field was photographed in rhodamine and fluorescein optics. Scale bar, $50 \mu \mathrm{m}$. ED 16.5, A neurite growing along a myotube is SV positive from its distal tip (arrow) back to where it branches from the main nerve trunk (arrowhead). PN 2, SV staining is observed in neurites leading to or between axon terminals, as well as in terminal sprouts characteristic for this stage of development (arrows). 


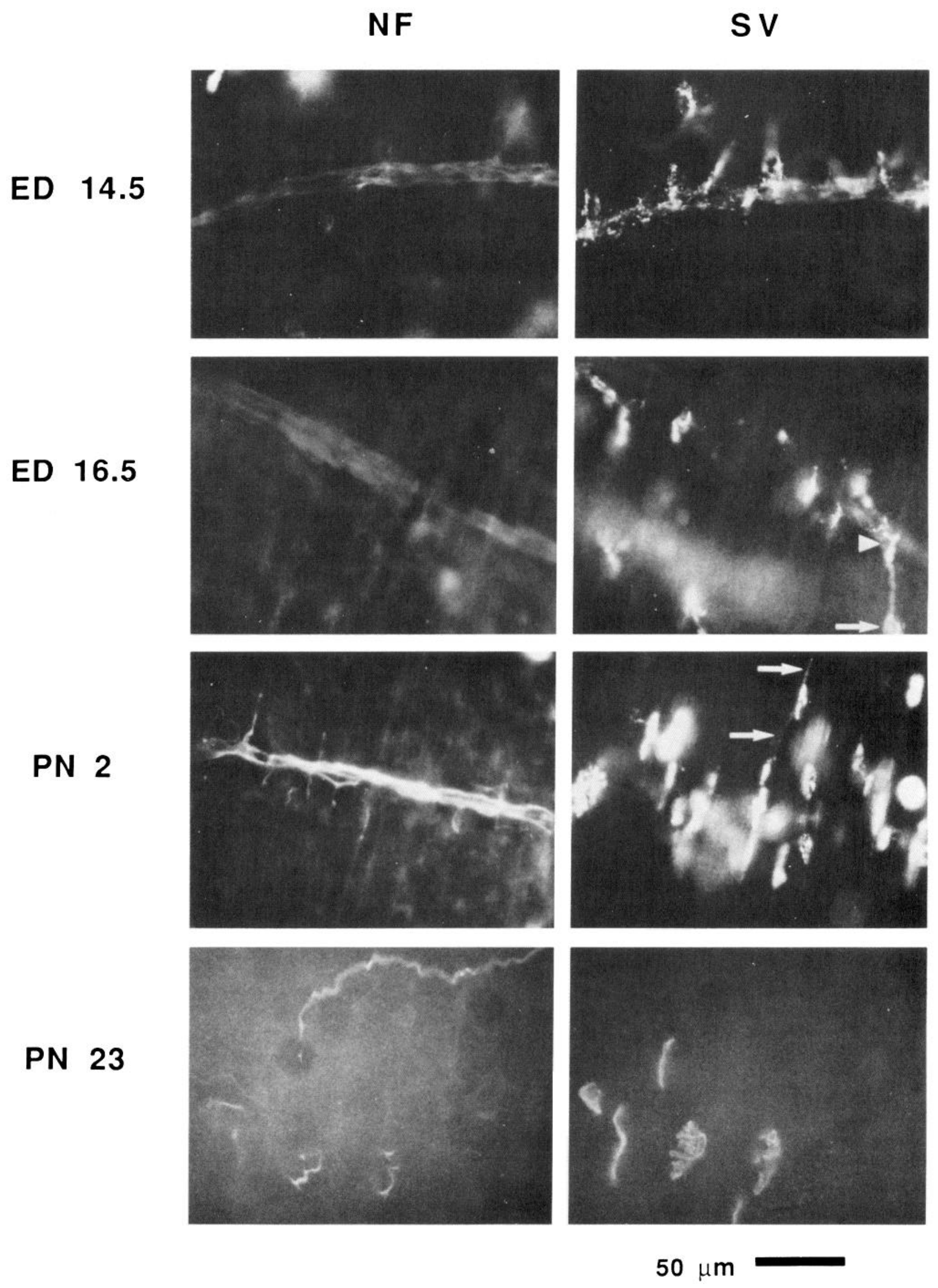




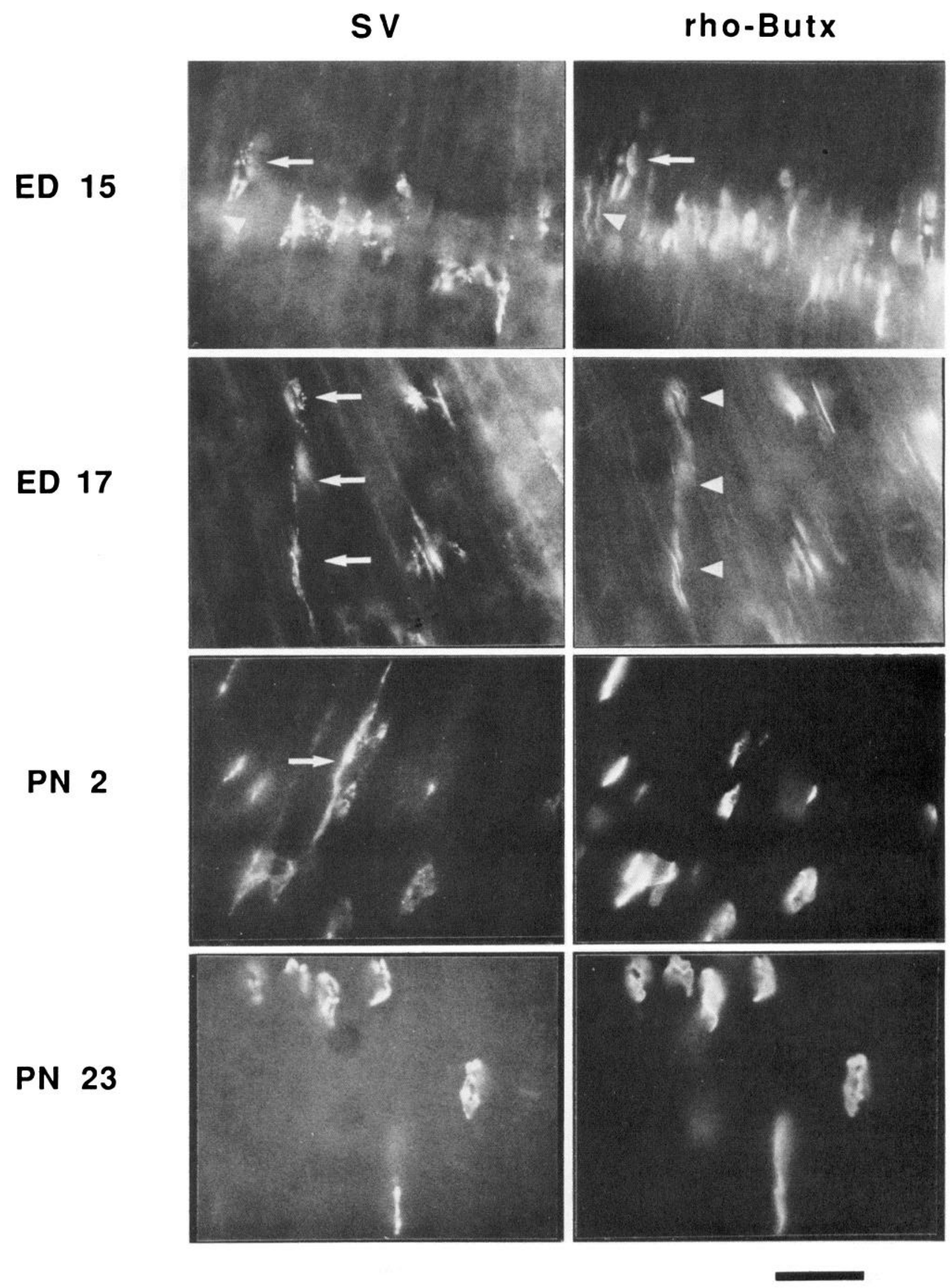


development in vivo, SV protein is present throughout long lengths of neurites as well as in growth cones. In diaphragm muscles from ED 14 mice, for instance, growing neurite branches stained for SV protein as far proximally as the main nerve trunk, and in some cases within the trunk (Fig. 4). During further development, SV protein becomes progressively restricted to more distal segments of the neurites. As late as PN 7, SV protein immunofluorescence was still detected in neurites leading to nerve terminals, as well as in the terminal sprouts present during the neonatal period (Figs. 4, 5). The adult distribution of SV protein is not achieved until the second and third postnatal weeks.

A similarly broad distribution of SV protein in growing neurites has been seen in other studies of neuronal development. Immunocytochemical staining of cross sections of embryonic and neonatal Torpedo electric organ (Vijay Sarthy and Bacon, 1985), rat retina (Mason, 1986), and cat cerebral cortex (Chun and Shatz, 1988) has revealed the presence of SV proteins in preterminal regions of growing neurites. In cat cortex, for example, SV proteins do not become localized exclusively to the adult synaptic region until 3 months after birth (Chun and Shatz, 1988).

The localization of SV proteins to nerve terminals appears to be a relatively late event in synaptogenesis at the neuromuscular junction, occurring at about the same time as physiological changes in transmitter release. During the second postnatal week, there is an increase both in miniature endplate potential frequency and in the safety margin for synaptic transmission (Redfern, 1970; Dennis, 1981). During this same period, a change in AChR subunit structure and channel kinetics occurs (Fischbach and Schuetze, 1980; Mishina et al., 1986), postsynaptic folds are elaborated (Kelly and Zacks, 1969) and polyneuronal innervation is lost (Redfern 1970; Brown et al., 1976).

Several recent experiments have shown that $\mathrm{ACh}$ is released from the growth cones of neurons in the absence of muscle contact (Hume et al., 1983; Young and Poo, 1983). The distribution of SVs over long lengths of neurites in early development may mean that transmitter release can occur from sites proximal to the growth cone as well. Release from these sites might be an important factor in the ability of nerves to establish functional nerve-muscle contacts at regions other than the terminal growth cone (Rodriguez-Marin and Cohen, 1988). Alternatively, the broad distribution of SV proteins early in development, at a time when only few postsynaptic potentials can be recorded (Dennis, 1981), raises the possibility that they play another role in growing neurites.

\section{$N F$ protein}

Both during development and in the adult, NF protein appears to have a distribution that is almost exactly complementary to that of SV protein. In the adult, NF protein occupies the axon up to the base of the nerve terminal. During development, as SV protein becomes gradually restricted to the terminal, the distribution of NF protein extends distally, reaching the ter- minal area only 1-2 weeks postnatally. Throughout development SV protein and NF protein appear to occupy contiguous, but mutually exclusive regions of the neurite. We have observed a similar segregation of NF protein and SV protein into separate neurite branches in cultures of mouse spinal cord cells (M. T. Lupa and Z. W. Hall, unpublished observations). NFs are thought to provide mechanical strength to axons and possibly to regulate axon diameter (Hoffman et al., 1984). They are metabolically very stable structures, lacking the "dynamic instability" of microtubules and microfilaments (see Mitchison and Kirschner, 1988). Therefore, the extension of NFs into a region of neurite and the corresponding loss of synaptic vesicles may mark the change from a plastic state in which new synaptic contacts can be made to a more stable, synaptically inactive state. A similar conclusion was reached by Hoffman (1989) after comparing mRNA levels for beta tubulin and NF proteins in both developing and regenerating axons.

\section{ACh receptor}

The general features of the formation of $\mathrm{AChR}$ clusters observed here are similar to those found in previous light and electron microscope studies (Bevan and Steinbach, 1977; Slater, 1982; Ziskind-Conhaim et al., 1984; Linden et al., 1988). Our experiments differed from previous studies, however, in that we were able to observe simultaneously the position of neurites, as well as of AChR clusters. Surprisingly, we found that when clusters were first detected, at ED 14-15, about half of them were not aligned with neurites. Aggregates of AChR without associated neurites have also been seen in embryonic chick wing muscle (Jacob and Lentz, 1979; Smith and Slater, 1983) and Torpedo electric organ (Fiedler et al., 1986). Other authors have observed that receptor aggregates extend beyond the axon terminal at the earliest nerve-muscle contacts in developing muscles (Matthews-Bellinger and Salpeter, 1983; Smith and Slater, 1983). The lack of complete correspondence between AChR patches and neurites suggests that direct nerve-muscle contact is not required for the induction of $\mathrm{AChR}$ clusters and that factors released by the nerve may be responsible (Podleski et al., 1978; Jessel et al., 1979; Godfrey et al., 1984). Alternatively, the clusters may represent sites of contact from which neurites have withdrawn.

Within 12-36 hr after the initial formation of AChR patches, all of them become aligned with neurites. These NARCs appear identical to those seen in cocultures of nerve and muscle (Anderson and Cohen, 1977) and provide evidence for a contactmediated effect on AChR clustering. The very precise alignment of the AChR clusters with neurites suggests that a remodeling process occurs to bring pre- and postsynaptic elements into register.

\section{Summary}

Our results can be summarized by a scheme in which there are 4 distinct stages of development of the neuromuscular junction (Fig. 6). In the first stage, AChR clusters appear at or near the

\footnotetext{
Figure 5. Distribution of SV protein and AChRs at developing neuromuscular junctions. Intact mouse diaphragms were immunostained with antibodies to the glycoprotein SV2 (SV) and with rhodamine-conjugated $\alpha$-bungarotoxin ( $r h o-B u t x)$. Scale bar, $50 \mu \mathrm{m}$ for ED 15 and ED $17 ; 30$ $\mu \mathrm{m}$ for PN 2 and PN 23. ED 15, Some AChR clusters are aligned with growing neurites (arrows), while others are not (arrowheads). All of the AChR clusters appear in this narrow band in the vicinity of the nerve. ED 17, All of the AChR clusters are NARCs. One SV-containing neurite courses across several myotubes (arrows) and induces NARCs on each of them (arrowheads). PN 2, SV-containing neurites can still be observed leading to or between nerve terminals (arrows), but no rho-Butx fluorescence is associated with these neurites.
} 
I. Initial Contact
ED 14-15

II. Induction of NARCs ED 16-18

\section{Immature NMJ} Birth-PN 7

\section{Mature NMJ Adult}
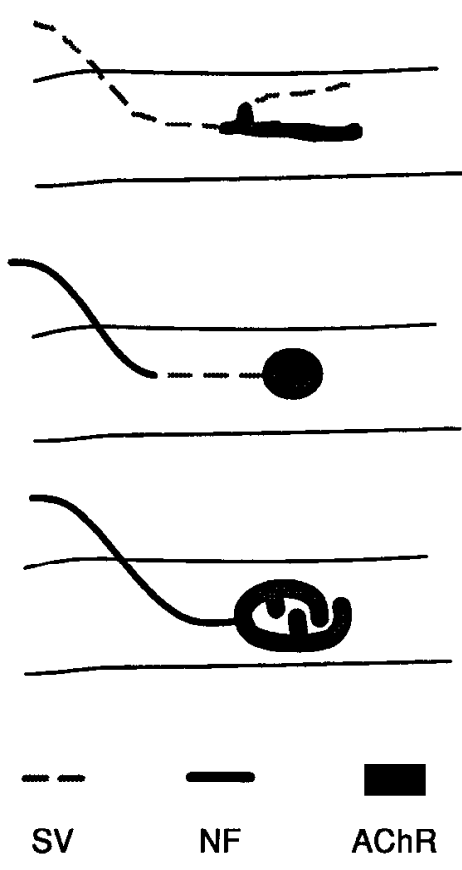

Figure 6. Stages of neuromuscular junction development, illustrating the progressive accumulation of SV protein, NF protein, and AChR in specific regions of the synapse. Stage I (ED 14-15), A short SV-containing neurite grows along the newly formed myotube, and an AChR cluster forms in the near vicinity of this neurite. Stage II (ED 16-18), The SV-accumulating neurite extends and branches out over the myotube, and the AChR cluster is now in precise alignment with a portion of the neurite. Stage III (birth-PN 7), An oval accumulation of SV protein has formed in the neurite, indicating the presence of an immature nerve terminal; the pattern of the AChR patch corresponds closely to the area under this terminal. NF protein has partially filled the axon leading to the terminal, but the distal part of the preterminal axon is still NF negative and SV positive. Stage IV (adult), At the mature adult neuromuscular junction SV proteins are concentrated in and confined to the nerve terminal, and the pattern of the AChR patch follows exactly the pattern of the SV-positive nerve terminal. NF protein is found in the entire preterminal axon, and sometimes weakly stains the proximal portion of the terminal itself.

sites of contact between muscle fibers and neurites. Most of the neurites contain synaptic vesicles and have few NFs. In stage II, all AChR clusters are associated with neurites, and there is very precise alignment between AChRs on the postsynaptic membrane and the neurites containing synaptic vesicles which extend along the muscle surface. Stage III is characterized by an cnlargement of the presynaptic nerve ending, marked by accumulation of synaptic vesicles, and a corresponding enlargement of the AChR patch on the postsynaptic membrane to form an oval aggregate. At this stage, neurites strongly staining for NFs are first seen in abundance on the muscle surface, and only a few neurites still have high concentrations of SVs. In the final stage, both the presynaptic terminal and the postsynaptic membrane assume the complex configuration seen in the adult (Steinbach, 1981; Slater, 1982). SVs are now exclusively confined to the terminal area, and NFs extend throughout the axons up to the nerve terminal.

These stages can be related to other events in development of the neuromuscular junction. For example, the focal accumulation of acetylcholinesterase and the appearance of a distinct basal lamina at the synapse occur during stage II (Bevan and Steinbach, 1977; Chiu and Sanes, 1984). The basal lamina in regenerating adult muscle has the ability to bring pre- and postsynaptic elements into topographic register (Sanes et al., 1978) and presumably plays a similar role in development. Its appearance at this stage may be related to the precise alignment of AChRs with the nerve endings. Stage III corresponds to the time at which AChRs become metabolically stabilized (Reiness and Weinberg, 1981) and the AChR clusters become more resistant to dispersal (Block and Steinbach, 1981). These events may signal a change in association of AChRs with the cytoskeletal or extracellular matrix. The final maturational events occur during stage IV, in postnatal life. At this time, the subunit composition and channel kinetics of the AChR change (Fischbach and Schuetze, 1980; Mishina et al., 1986), subsynaptic folds appear (Tervainen, 1968; Kelly and Zacks, 1969), and polyneuronal innervation is eliminated (Redfern, 1970; Brown et al., 1976). The latter event may be of particular importance with respect to the presynaptic changes that we have obscrved during this stage. The loss of SVs and appearance of NFs in the preterminal axon presumably represents a loss of plasticity in the axon that only occurs when the final pattern of innervation is completely established.

\section{References}

Anderson, M. J., and M. W. Cohen (1977) Nerve-induced and spontaneous redistribution of acetylcholine receptors on cultured muscle cells. J. Physiol. (Lond.) 268: 757-773.

Bevan, S., and J. H. Steinbach (1977) The distribution of alpha-bungarotoxin binding sites on mammalian skeletal muscle developing in vivo. J. Physiol. (Lond.) 267: 195-213.

Bixby, J. L., and L. F. Reichardt (1985) The expression and localization of synaptic vesicle antigens at neuromuscular junctions in vitro. J. Neurosci. 5: 3070-3080.

Bloch, R. J., and J. H. Steinbach (1981) Reversible loss of acetylcholine receptor clusters at the developing rat neuromuscular junction. Dev. Biol. 81: 386-391.

Braithwaite, A. W., and A. J. Harris (1979) Neural influence on acetylcholine receptor clusters in embryonic development of skeletal muscles. Nature 279: 549-551.

Brown, M. C., J. K. S., Jansen, and D. C. Van Essen (1976) Polyneuronal innervation of skeletal muscle in new-born rats and its elimination during maturation. J. Physiol. (Lond.) 261: 387-422.

Buckley, K., and R. B. Kelly (1985) Identification of a transmembrane glycoprotein specific for secretory vesicles of neural and endocrine cells. J. Cell Biol. 100: 1284-1294.

Chiu, A. Y., and J. R. Sanes (1984) Development of basal lamina in synaptic and extrasynaptic portions of embryonic rat muscle. Dev. Biol. 103: 456-467.

Chun, J. J. M., and C. J. Shatz (1988) Redistribution of synaptic vesicle antigens is correlated with the disappearance of a transient synaptic zone in the developing cerebral cortex. Neuron 1:297-310.

Cohen, M. W., E. Rodriguez-Marin, and E. M. Wilson (1987) Distribution of synaptic specializations along isolated motor units formed in Xenopus nerve-muscle cultures. J. Neurosci. 7: 2849-2861.

Coutcaux, R., and M. Pecot-Dechavassine (1970) Vesicles synaptiques et poches au niveau des "zones actives" de la jonction neuromusculaire. C. R. Acad. Sci. (Paris) 271: 2346-2349.

De Camilli, P., R. Cameron, and P. Greengard (1983) Synapsin I (Protein I), a nerve terminal-specific phosphoprotein. I. Its general distribution in synapses of the central and peripheral nervous system demonstrated by immunofluorescence in frozen and plastic sections. J. Cell Biol. 96: 1337-1354. 
De Camilli, P., M. Vitadello, M. P. Canevini, R. Zanoni, R. Jahn, and A. Gorio (1988) The synaptic vesicle proteins synapsin I and synaptophysin (protein P38) are concentrated both in efferent and afferent nerve endings of skeletal muscle. J. Neurosci. 8: 1625-1631.

Dennis, M. J. (1981) Development of the neuromuscular junction: Inductive interactions between cells. Annu. Rev. Neurosci. 4: 43-68.

Dennis, M. J., L. Ziskind-Conhaim, and A. J. Harris (1981) Development of neuromuscular junctions in rat embryos. Dev. Biol. 81: 266-279.

Donahue, S. P., J. G. Wood, and A. W. English (1988) On the role of the $200-\mathrm{kDa}$ neurofilament protein at the developing neuromuscular junction. Dev. Biol. 130: 154-166.

Fambrough, D. (1979) Control of acetylcholine receptors in skeletal muscle. Physiol. Rev. 59: 165-227.

Fertuck, H. C., and M. M. Salpeter (1976) Quantitation of junctional and extrajunctional acetylcholine receptors by electron microscope autoradiography after ${ }^{125} \mathrm{I}$-alpha-bungarotoxin binding at mouse neuromuscular junctions. J. Cell Biol. 69: 144-158.

Fiedler, W., E. Borroni, and P. Ferretti (1986) An immunohistochemical study of synaptogenesis in the electric organ of Torpedo marmorata by use of antisera to vesicular and presynaptic plasma membrane components. Cell Tissue Res. 246: 439-446.

Fischbach, G. D., and S. M. Schuetze (1980) A postnatal decrease in acetylcholine channel open time at rat endplates. J. Physiol. (Lond.) 303: 125-137.

Froehner, S. C., A. A. Murnane, M. Tobler, H. B. Peng, and R. Sealock (1987) A postsynaptic $M_{r} 58,000(58 \mathrm{~K})$ protein concentrated at acetylcholine receptor-rich sites in Torpedo electroplaques and skeletal muscle. J. Cell Biol. 104: 1633-1645.

Godfrey, E. W., R. M. Nitkin, B. G. Wallace, I. I. Rubin, and U. J. McMahan (1984) Components of Torpedo electric organ and muscle that cause aggregation of acetylcholine receptors on cultured muscle cells. J. Cell Biol. 99: 615-627.

Gown, A. M., and A. M. Vogel (1984) Monoclonal antibodies to human intermediate filament proteins. II. Distribution of filament proteins in normal human tissues. Am. J. Pathol. 114: 309-321.

Gu, Y., and Z. W. Hall (1988) Immunological evidence for a change in subunits of the acetylcholine receptor in developing and denervated rat muscle. Neuron 1: 117-125.

Hirokawa, W., M. A. Glicksman, and M. B. Willard (1984) Organisation of mammalian neurofilament polypeptides within the neuronal cytoskeleton. J. Cell Biol. 98: 1523-1536.

Hoffman, P. N. (1989) Distinct patterns of gene expression during longitudinal and radial growth of axons. J. Cell Biol. 107: 665a(3762)

Hoffman, P. N., J. W. Griffin, and D. L. Price (1984) Control of axonal caliber by neurofilament transport. J. Cell Biol. 99: 705-714.

Hume, R. I., L. W. Role, and G. D. Fischbach (1983) Acetylcholine release from growth cones detected with patches of acetylcholine receptor-rich membranes. Nature 305: 632-634.

Jacob, M., and T. Lentz (1979) Localization of acetylcholine receptors by means of horseradish peroxidase-alpha-bungarotoxin during the formation and development of the neuromuscular junction in the chick embryo. J. Cell Biol. 82: 195-211.

Jessel, T. M., R. E. Siegel, and G. D. Fischbach (1979) Induction of acetylcholine receptors on cultured skeletal muscle by a factor extracted from brain and spinal cord. Proc. Natl. Acad. Sci. USA 76: $5397-5401$.

Kelly, A. M., and S. I. Zacks (1969) The fine structure of motor endplate morphogenesis. J. Cell Biol. 42: 154-169.

Linden, D. C., S. M. Jerian, and M. S. Letinsky (1988) Neuromuscular junction development in the cutaneous pectoris muscle of Rana catesbeiana. Exp. Neurol. 99: 735-760.

Mason, C. A. (1986) Axon development in mouse cerebellum: Embryonic axon forms and expression of synapsin I. Neuroscience 19: 1319-1333.

Matthew, W. D., L. Tsavaler, and L. F. Reichardt (1981) Identification of a synaptic vesicle-specific membrane protein with a wide distribution in neuronal and neurosecretory tissue. J. Cell Biol. 91: 257269.

Matthews-Bellinger, J. A., and M. M. Salpeter (1983) Fine structural distribution of acetylcholine receptors at developing mouse neuromuscular junctions. J. Neurosci. 3: 644-657.
Mishina, M., T. Takai, K. Imoto, M. Noda, T. Takahashi, S. Numa, C. Methfessel, and B. Sakmann (1986) Molecular distinction between fetal and adult forms of muscle acetylcholine receptor. Nature 321: 406-411.

Mitchison, T., and M. Kirschner (1988) Cytoskeletal dynamics and nerve growth. Neuron $1: 761-772$.

Platt, J. L., and A. F. Michael (1983) Retardation of fading and enhancement of intensity of immunofluorescence by p-phenylenediamine. J. Histochem. Cytochem. 31: 840-842.

Podleski, T. R., D. Axelrod, P. Ravdin, I. Greenberg, M. M. Johnson, and M. M. Salpeter (1978) Nerve extract induces increase and redistribution of acetylcholine receptors on cloned muscle cells. Proc. Natl. Acad. Sci. USA 75: 2035-2039.

Ravdin, P., and D. Axelrod (1977) Fluorescent tetramethylrhodamine derivatives of alpha-bungarotoxin: Preparation, separation, and characterization. Anal. Biochem. 80: 585-592.

Redfern, P. A. (1970) Neuromuscular transmission in new-born rats. J. Physiol. (Lond.) 209: 701-709.

Reichardt, L. F., and R. B. Kelly (1983) A molecular description of nerve terminal function. Annu. Rev. Biochem. 52: 871-926.

Reiness, C. G., and C. B. Weinberg (1981) Metabolic stabilization of acetylcholine receptors at newly formed neuromuscular junctions in rats. Dev. Biol. 84: 247-254.

Rodriguez-Marin, E., and M. W. Cohen (1988) The capacity of nongrowth cone portions of neurites to trigger the development of a postsynaptic specialization. Soc. Neurosci. Abstr. 14: 210.10.

Salpeter, M. M., and R. H. Loring (1986) Nicotinic acetylcholine recptors in vertebrate muscle: Properties, distribution and neural control. Prog. Neurobiol. 25: 297-325.

Sanes, J. R., and Z. W. Hall (1979) Antibodies that bind specifically to synaptic sites on muscle fibre basal lamina. J. Cell Biol. 83: 357370.

Sanes, J. R., L. M. Marshall, and U. J. McMahan (1978) Reinnervation of muscle fiber basal lamina after removal of myofibers. Differentiation of regenerating axons at original synaptic sites. J. Cell Biol. 78: 176-198.

Shaw, G. (1987) Neurofilaments: Abundant but mysterious neuronal structures. Biol. Essays 4: 161-166.

Shaw, G., E. Debus, and K. Weber (1984) The immunological relatedness of neurofilament proteins of higher vertebrates. Eur. J. Cell Biol. 34: 130-136.

Slater, C. R. (1982) Neural influence on the postnatal changes in acetylcholine receptor distribution at nerve-muscle junctions in the mouse. Dev. Biol. 94: 23-30.

Smith, M. A., and C. R. Slater (1983) Spatial distribution of acetylcholine receptors at developing chick neuromuscular junctions. J. Neurocytol. 12: 993-1005.

Steinbach, J. H. (1981) Developmental changes in acetylcholine receptor aggregates at rat skeletal neuromuscular junctions. Dev. Biol. 84: 267-276.

Tervainen, H. (1968) Development of the myoneural junction in the rat. Z. Zellforsch. Mikrosk. Anat. 87: 249-265.

Vijay Sarthy, P., and W. Bacon (1985) Developmental expression of a synaptic vesicle-specific protein in the rat retina. Dev. Biol. 112 . 284-291.

Wessendorf, M. W., N. M. Appel, and R. Elde (1987) Simultaneous observation of fluorescent retrogradely labeled neurons and the immunofluorescently labeled fibers apposing them using Fluoro-Gold and antisera labeled with the blue fluorochrome 7-amino-4-methylcoumarin-3-acetic acid (AMCA). Neurosci. Lett. 82: 121-126.

Wiedenmann, B., and W. W. Franke (1985) Identification and localization of synaptophysin, an integral membrane glycoprotein of $\mathrm{M}_{\mathrm{r}}$ 38,000 characteristic of presynaptic vesicles. Cell 41: 1017-1028.

Young, S. H., and M.-M. Poo (1983) Spontaneous release of transmitter from growth cones of embryonic neurones. Nature 305: 634 637.

Ziskind-Conhaim, L., I. Green, and Z. W. Hall (1984) Redistribution of acetylcholine receptors on developing rat myotubes. J. Neurosci. 4: 2346-2349. 